\title{
AGENDA 2030 PARA 0 DESENVOLVIMENTO SUSTENTÁVEL: UMA LEITURA DE POLÍTICA PÚBLICA NA CLAVE DA BIBLIOTECA ESCOLAR
}

2030 AGENDA FOR THE SUSTAINABLE DEVELOPMENT: A READING PUBLIC POLICY IN THE LIGHT OF THE SCHOOL LIBRARY

AGENDA 2030 PARA EL DESARROLLO SOSTENIBLE: UNA LECTURA DE POLÍTICA PÚBLICA LA CLAVE DE LA BIBLIOTECA ESCOLAR

${ }^{1}$ Claudio Marcondes de Castro Filho

${ }^{1}$ Universidade de São Paulo

Correspondência

${ }^{1}$ Claudio Marcondes de Castro Filho (D)

Universidade de São Paulo

São Paulo, SP

E-mail: claudiomarcondes@ @ffclrp.usp.br

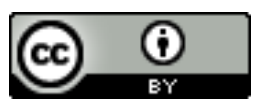

JITA: DE. School libraries.

Submetido em: 07/11/2017

Aceito em: 11/06/2018

Publicado em: 27/08/2018 
RESUMO: Este artigo apresenta os 17 Objetivos de Desenvolvimento Sustentável (ODS), programa da Organização da Nações Unidas que visa transformar o mundo. Essa apresentação é interpretada à luz dos parâmetros da biblioteca escolar. A articulação entre o desenvolvimento sustentável e os objetivos da biblioteca escolar permite situar as contribuições no âmbito mais amplo de uma política pública para a educação. Essa articulação gerou alguns pressupostos como: possibilitar o aumento do índice de leitura; a biblioteca escolar deve fazer parte do movimento social que busca efetivar as políticas públicas educacionais e culturais; fornecer instrumental necessário para a formação, o desenvolvimento e o aprimoramento das competências do aluno; abrir um espaço de criação e de compartilhamento de experiências. Como conclusão, entendemos que a existência da biblioteca escolar pode contribuir para propor soluções para os objetivos do desenvolvimento sustentável.

PALAVRAS-ChavE: Biblioteca escolar. Desenvolvimento sustentável. Educação - Biblioteca. Política pública.

ABSTRACT: This article presents the 17 OSD (Objectives of Sustainable Development), a program of the United Nations for transforming the world. This presentation is interpreted in the light of the parameters of the school library. The articulation between the sustainable development and the objectives of the school library allows to place the contributions within the broader scope of a public policy for education. This articulation generated some assumptions such as: to increase the reading index; the library school must be part of the social movement which seeks to set up educational and cultural public policies; to provide instrumental required for the training, development and improvement of the student's skills; to open up a space of creation and sharing experiences. In conclusion, we understand that the existence of the school library can contribute to propose solutions for sustainable development's objectives.

KEYWORDS: School library. Sustainable development. Library -Education. Public policy.

RESUMEN: Este artículo presenta los 17 ODS (Objetivos de Desarrollo Sostenible), programa de la Organización de las Naciones Unidas para transformar el mundo. Esta presentación se interpreta a la luz de los parámetros de la biblioteca escolar. La articulación entre el desarrollo sostenible y los objetivos de la biblioteca escolar permite situar las contribuciones en el ámbito más amplio de una política pública para la educación. Esta articulación generó algunos supuestos como: posibilitar el aumento del índice de lectura; la biblioteca escolar debe formar parte del movimiento social que busca efectivizar las políticas públicas educativas y culturales; proporcionar instrumental necesario para la formación, el desarrollo y el perfeccionamiento de las competencias del alumno; abrir un espacio de creación y de compartir experiencias. Como conclusión, entendemos que la existencia de la biblioteca escolar puede contribuir a proponer soluciones a los objetivos del desarrollo sostenible.

PAlabRas Clave: Biblioteca escolar. Desarrollo sostenible. Biblioteca - Educación. Politica pública. 


\section{INTRODUÇÃ̃o}

O ano de 2015 poderia passar à história como o ano de definição dos 17 Objetivos de Desenvolvimento Sustentável (ODS), programa de ação em dimensão mundial para a melhoria das condições de vida dos povos e do planeta, fixados em uma conferência de cúpula da Organização das Nações Unidas (ONU), realizada em Nova Iorque entre 25 e 27 de setembro. Tratou-se de uma nova agenda de ação prevista até 2030, baseada nos progressos e lições aprendidos com os oito 8 Objetivos de Desenvolvimento do Milênio (ODM), entre 2000 e 2015.

A agenda é fruto do trabalho conjunto de governos e cidadãos de todo o mundo para criar um novo modelo global que possa acabar com a pobreza, promover a prosperidade e o bem-estar de todos, proteger o ambiente e combater as alterações climáticas. A partir de então, as Nações Unidas desenvolveram formas de cooperação e parcerias com governos, sociedade civil e outros agentes sociais, a fim de tornar possível um projeto tão ambicioso.

Este artigo pretende apresentar e descrever as origens dos 17 ODS e, especificamente, as características do ODS 4 "Educação de Qualidade", que visam transformar o mundo, e interpretá-los à luz dos parâmetros da biblioteca escolar. Tais parâmetros também serão considerados segundo os conceitos apresentados nas Diretrizes da Biblioteca Escolar (2015) da International Federation of Library Associations and Institutions - IFLA (Federação Internacional das Associações de Bibliotecários e de Bibliotecas), que trata dos objetivos, orientações, recursos humanos coleções, programas educativos e apoio às bibliotecas escolares, com o propósito de auxiliar os profissionais de biblioteca escolar e decisores educativos nos seus esforços para assegurar que todos os alunos e professores têm acesso a programas e serviços de biblioteca escolar eficazes, prestados por profissionais qualificados e de outras referências pertinentes, como as Diretrizes da IFLA sobre os serviços da biblioteca pública (2013), que trata da missão, objetivos, financeiro, coleções, recursos humanos, gestão e marketing.

Para esta investigação foi utilizada a pesquisa exploratória, que tem como finalidade desenvolver e elucidar conceitos e ideias sobre o desenvolvimento sustentável e a biblioteca escolar, e que envolvem a pesquisa bibliográfica e documental. Segundo Gil (1999, p. 43), este método tem como objetivo "[...] proporcionar uma visão geral, de tipo aproximativo, a cerca de determinado fato". Para Marconi e Lakatos (2006), na pesquisa bibliográfica utilizase documentação de natureza diversa e publicada em diferentes suportes.

Esta pesquisa pretende configurar, assim, um ponto de vista que possa ser singular e original, na expectativa de contribuir com o debate sobre alguns aspectos da educação brasileira. Pretende ainda propor formas de se pensar e abordar a busca de alternativas para a melhoria de qualidade de vida entendida como cultura e educação de crianças e jovens, extratos que formam a matriz de novas gerações e esperanças de um país melhor. A

\begin{tabular}{|c|c|c|c|c|c|}
\hline (C) RDBCI: Rev. Digit. Bibliotecon. Cienc. Inf. & Campinas, SP & v.16 & n.3 & p. $355-372$ & set./dez. 2018 \\
\hline
\end{tabular}


articulação entre os objetivos de desenvolvimento sustentável e os objetivos da biblioteca escolar permite situar a análise no âmbito mais amplo de uma política pública, na medida em que coloca o papel da biblioteca escolar no palco do desenvolvimento sustentável, ou seja, como agente atuante na constituição de um mundo mais justo socialmente.

\section{OBJETIVOS DO DESENVOLVIMENTO DO MILÊNIO}

Base dos 17 Objetivos de Desenvolvimento Sustentável (ODS), os 8 Objetivos do Desenvolvimento do Milênio (ODM) têm como proposta a melhoria da vida dos seres humanos e também a melhoria das condições sociais, culturais, econômicas e educacionais no mundo.

O primeiro objetivo trata de "erradicar a fome e a pobreza extrema" (ODM 1), uma vez que o relatório (março de 2010) do Secretário-Geral da ONU realçava que "no mundo inteiro, o número de pessoas com fome aumentou de 842 milhões em 1990/92 para 1,02 mil milhões de pessoas em 2009" (CENTRO, 2010). No entanto, segundo o Relatório The State of Food Security and Nutrition in the World 2017 (2017), após uma trajetória de queda, que durou mais de uma década, a fome em todo mundo parece estar aumentando de novo, afetando atualmente $11 \%$ da população mundial. Além do aumento na proporção da população mundial que sofre de fome crônica (prevalência de desnutrição), o número de pessoas subnutridas no planeta também aumentou para 815 milhões, ante 777 milhões em 2015. O relatório aponta ainda que conforme refletido no ODS 2, um dos maiores desafios que o mundo enfrenta é como garantir que uma população global crescente - projetada para aumentar para cerca de 10 bilhões até 2050 - tenha alimento suficiente para suprir suas necessidades nutricionais. Apesar das fontes serem diversificadas com relação ao aumento de pessoas subnutridas, o número ainda é muito elevado.

Em 2012, o Brasil reduziu a pobreza e a fome: de 25,5\% em 1990 para 3,5\%. Em 2012, a proporção de se estar em situação de pobreza extrema entre uma família liderada por analfabeto e uma família cujo líder possuía curso superior era de 11:1. Em 1990, a chance era 144 vezes maior para o primeiro caso (PROGRAMA, 2015a). Segundo o documento das Nações Unidas Brasil intitulado Documentos Temáticos: Objetivos de Desenvolvimento Sustentável $1 \cdot 2 \cdot 3 \cdot 5 \cdot 9 \cdot 14$, o Brasil em 2014 reduziu para menos de 5\% a taxa da população vivendo em condições de subalimentação, limite abaixo do qual se considera que a fome deixa de ser um problema estrutural para o país.

Considerando os índices adotados pela ONU para monitoramento do ODM 1, o Brasil alcançou as metas internacionais e nacionais, e foi um dos países que mais colaborou para que a meta deste objetivo fosse atingida.

O segundo objetivo apresenta, no âmbito educativo, propostas para "alcançar o ensino primário universal" (ODM 2), no sentido de que todas as crianças terminem um ciclo completo de ensino primário. No Brasil, a procura pela universalização da educação primária centrou-se na ampliação do acesso obrigatório. Em 2012, jovens de 15 a 24 anos com ao

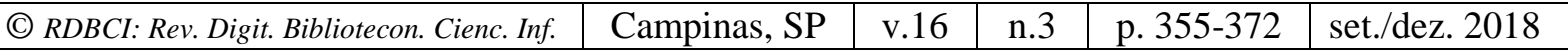


menos seis anos completos de estudo compunham a faixa de 84\%. Em 1990, a fatia era de 59,9\% (PROGRAMA, 2015b). Para crianças de 7 a 14 anos, a desigualdade do acesso à escola foi vencida por conta das políticas de ensino universal que diminuíram as carências de serviços educacionais.

O terceiro objetivo intenta "promover a igualdade entre os sexos e o empoderamento das mulheres" (ODM 3), para que as mulheres alcançassem melhores oportunidades de trabalho na sociedade civil e política. Segundo o relatório Global Gender Gap Report (2017), nesse ano o Brasil caiu para a $90^{\mathrm{a}}$ posição em ranking do Fórum Econômico Mundial sobre a igualdade entre homens e mulheres em 144 países. Em 2016, o país estava em 79 lugar, em

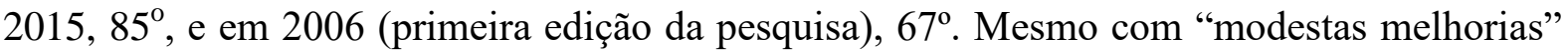
em termos econômicos e com uma relativa paridade nos indicadores de saúde e educação, as mulheres brasileiras ainda eram confrontadas com desafios no âmbito da representatividade política. No subíndice "Empoderamento Político", o Brasil caiu de $86^{\circ}$ lugar para $110^{\circ}$. De 513 deputados federais, 51 são mulheres (10\% do total). De 81 senadores, 13 são mulheres (16\%). No governo do presidente Michel Temer, de 28 ministros, 2 são mulheres (7\%). O relatório apontava que a renda média da mulher equivalia a $58 \%$ da renda do homem (mesmo índice de 2016). A “média do salário em 2017 era US\$ 11.132 (R\$ 36.330,00) para mulheres e US\$ 19.260 (R\$ 62.860,00) para homens”. No cenário econômico latino-americano, o Brasil estava na pior posição, atrás de "Argentina $\left(33^{\circ}\right)$, Colômbia $\left(36^{\circ}\right)$, Peru $\left(48^{\circ}\right)$, Uruguai $\left(56^{\circ}\right)$, Chile $\left(63^{\circ}\right)$ e México $\left(81^{\circ}\right)$ ". As mulheres brasileiras têm índices melhores em saúde e educação. Para cada aluno de ensino superior, as alunas tinham 1,4 das vagas. Quanto à expectativa de vida, as "mulheres contavam com 67,8 anos e os homens, 63,1 anos" (ALVARENGA, 2017, p.1) ${ }^{1}$.

O quarto objetivo atenta para "reduzir a mortalidade de crianças" (ODM 4). Alguns dados estatísticos mostravam que essa redução vinha acontecendo nas regiões em desenvolvimento, mas que seria necessário melhorar essa redução. Segundo o relatório da UNICEF (Fundo das Nações Unidas para a Infância) (2017), a cada dia de 2016, 15.000 crianças morreram antes do quinto aniversário, sendo que $46 \%$ morreram nos primeiros 28 dias de vida. O relatório Levels and trends in child mortality mostra que a proporção de mortes nos primeiros 28 dias de vida aumentou de $41 \%$ para $46 \%$, foram 5,6 milhões em 2016 e 9,9 milhões em 2000. Se as tendências ficarem estáveis, 60 milhões de crianças morrerão antes do quinto ano de vida entre 2017 e 2030, sendo metade recém-nascidos. Assim analisa o referido relatório, publicado pela UNICEF (2017).

O quinto objetivo trata de "melhorar a saúde materna" (ODM 5). Pesquisas do Programa das Nações Unidas para o Desenvolvimento (PNUD) (PROGRAMA, 2015c) indicavam que a redução da mortalidade materna brasileira foi melhor do que as médias de

\footnotetext{
${ }^{1}$ https://g1.globo.com/economia/noticia/brasil-cai-para-a-90-posicao-em-ranking-de-igualdade-entre-homens-emulheres.ghtml

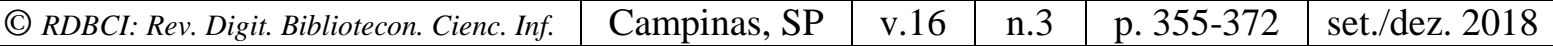


outras nações em desenvolvimento e da América Latina, apesar dos desafios ainda a serem enfrentados. De 1990 a 2011, a taxa de mortalidade caiu 55\%, de 141 para 64 mortes a cada 100 mil nascidos vivos. Em 2011, 99\% dos partos foram feitos em hospitais ou instituições de saúde, e $90 \%$ das gestantes fizeram quatro ou mais consultas pré-natais. O Brasil já conseguiu deter e inverter o crescimento da mortalidade por câncer de colo de útero, mas a mortalidade por câncer de mama ainda avança.

O sexto objetivo visa "combater o HIV, malária e outras doenças" (ODM 6). Segundo o (PROGRAMA, 2015d), há dez anos estava estável no Brasil a taxa de detecção de HIV/AIDS, com cerca de 20 por 100 mil habitantes diagnosticados por ano. O índice de mortalidade pela doença diminuiu. No âmbito do aumento crescente do potencial de diagnóstico, a estabilização da taxa de detecção apontaria para a interrupção da propagação da doença e a redução da incidência, tal como exigido pela meta deste ODM (PROGRAMA, 2015d).

O sétimo objetivo versa sobre a "sustentabilidade ambiental" (ODM 7). Uma das metas era reduzir a proporção da parcela da população sem acesso contínuo à água potável e ao saneamento básico (em 2012, a porcentagem já estava abaixo da metade da taxa de 1990) e, até 2020, almejava-se melhorar a vida de 100 milhões de pessoas que habitam regiões degradadas (em 2012, a porcentagem da população em condições de moradia urbana precárias estava em 36,6\%, face a 53,3\% em 1992). O Brasil é uma das reservas da biodiversidade mundial e, por meio da redução de taxas de desmatamento nos biomas nacionais (da Amazônia aos Pampas), participa da contribuição para preservar tal biodiversidade (PROGRAMA, 2015e).

O oitavo objetivo aborda uma "parceria mundial" (ODM 8) que pretendia, em cooperação com o setor privado, tornar acessíveis as novas tecnologias e seus benefícios, particularmente nas áreas da informação e das comunicações. Para expandir os modos de participação dos países em desenvolvimento dentro da perspectiva de uma reconfiguração da ordem econômica internacional, seja na reforma do sistema internacional, seja na relevância de sua atuação de estímulo ao desenvolvimento, a diplomacia brasileira centra esforços no multilateralismo comercial. De modo ativo e propositivo, o Brasil atua para garantir o sucesso da Rodada de Doha da OMC (Organização Mundial do Comércio), cujo objetivo central é fazer do sistema multilateral do comércio uma instância mais equilibrada e justa, contribuindo assim para o desenvolvimento socioeconômico (PROGRAMA, 2015f).

Dos oito objetivos de Desenvolvimento do Milênio, é o número dois que trata de educação. Quando é apresentada a questão da universalização do Ensino fundamental I, podemos imediatamente pensar na biblioteca escolar que segundo a Lei de Diretrizes e Bases da Educação Nacional - LDB (1996) o atendimento ao educando, no ensino fundamental público, pode ser ampliado por meio de programas suplementares de material didáticoescolar, transporte, alimentação e assistência à saúde e que podemos incluir a biblioteca 
escolar como estrutura para o ensino e aprendizagem, uma vez que as diretrizes da IFLA (2013) para biblioteca escolar preconiza recomendações que abrange as coleções, melhorias contínuas para o crescimento e desenvolvimento da biblioteca escolar, profissionais qualificados e principalmente a lesgilação sobre biblioteca escolar. Nesse aspecto, umas das missões da biblioteca escolar é "disponibilizar serviços de aprendizagem, livros e recursos que permitem a todos os membros da comunidade escolar tornarem-se pensadores críticos e utilizadores efetivos da informação em todos os suportes e meios de comunicação" (IFLA, 2015).

Com seus 17 Objetivos de Desenvolvimento Sustentável e suas 169 metas, a Agenda 2030, originada desses 8 Objetivos do Desenvolvimento do Milênio, é um programa de ação para a humanidade e o planeta, que busca a prosperidade, a justiça social, a paz e a liberdade, nas dimensões econômica, social e ambiental. Esses objetivos trouxeram desafios, e mesmo que alguns deles sejam alcançados, novamente a sociedade é convidada para se mobilizar e enfrentar novos desafios nos próximos 15 anos. Para tanto, a educação tem uma contribuição fundamental. E, nesse âmbito, a biblioteca escolar cumpre uma de suas funções mais nobres, em sentido mais amplo: a consolidação da cidadania e a educação para a justiça social.

\section{O DESENVOLVIMENTO SUSTENTÁVEL E A BIBLIOTECA ESCOLAR}

Sob a ótica da Biblioteca Escolar, escolhemos o ODS 4 "Educação de Qualidade" da Agenda 2030 como eixo deste artigo. Apresentaremos as declarações deste Objetivo de Desenvolvimento Sustentável e teceremos comentários que, em nosso entendimento, as vinculam à biblioteca escolar, que, cabe notar, não é mencionada em nenhum dos objetivos desta Agenda.

O ODS 4 "Assegurar a educação inclusiva e equitativa e de qualidade, e promover oportunidades de aprendizagem ao longo da vida para todas e todos" (NAÇÕES, 2015a, p. 1) trata de garantir uma educação de qualidade e justa que ofereça inclusão escolar (que, aqui, abarca também a inclusão digital, a social e outras) e de proporcionar para toda a sociedade brasileira oportunidades de aprendizagem ao longo da vida.

Este é um dos objetivos básicos da biblioteca escolar, cuja missão é fornecer informações vitais (no sentido de importantes à vida mesma) para a sociedade que, atualmente, estrutura-se sobre os pilares do conhecimento e da informação. Por sua constituição, a biblioteca escolar desenvolve nos alunos as competências para a aprendizagem ao longo da vida, instigando a imaginação, a criação e a curiosidade, contribuindo para o desenvolvimento de cidadãos (IFLA 2000).

Com relação às metas do ODS 4, apresentamos as seguintes premissas: 
Na meta 4.1 do ODS 4, "resultados de aprendizagem relevantes e eficazes" (NAÇÕES, 2015a, p. 1). A biblioteca escolar tem influência marcante, e de longo alcance, no processo de aprendizagem ao longo da vida, por possibilitar o aumento do índice de leitura, que, por sua vez, contribui para o aumento do PISA (Programme for International Student Assessment). Entre os objetivos da biblioteca escolar segundo o manifesto da IFLA (Federação Internacional das Associações de Bibliotecários e de Bibliotecas) está o de "criar e manter nas crianças o hábito e o prazer da leitura, da aprendizagem e da utilização das bibliotecas ao longo da vida" (IFLA 2000, p. 2).

A biblioteca escolar é também um espaço de produção cultural onde crianças e jovens são criadoras, e não apenas consumidoras, de cultura. De acordo com Retratos da Leitura no Brasil (2016), não consta a biblioteca escolar como fator que pode influenciar a escolha de um livro, e apenas um em cada quatro brasileiros domina plenamente as habilidades de leitura, escrita e matemática. Outro objetivo da biblioteca escolar, segundo o manifesto da IFLA, está afinado com a meta 4.1 do ODS 4, pois contempla um resultado de importância e eficácia: "promover a leitura, os recursos e serviços da biblioteca escolar junto da comunidade escolar e fora dela" (IFLA 2000, p. 2).

$\mathrm{Na}$ meta 4.2, "desenvolvimento de qualidade na primeira infância, cuidados e educação pré-escolar" (NAÇÕES, 2015a, p. 1). A biblioteca escolar é uma primeira oportunidade concreta de acesso ao patrimônio científico e cultural. É um espaço ativo de ação pedagógica, de incentivo e de práticas à leitura, com inserção de atividades lúdicas complementares ao processo tradicional de ensino-aprendizagem. Deve fazer parte do movimento social que busca efetivar as políticas públicas educacionais e culturais. Deve contemplar espaços para aprendizagem de um idioma estrangeiro.

Assim, é necessário trabalhar a influência dos pais com a tecnologia junto às crianças de 5 a 10 anos: " $34 \%$ nessa faixa etária utiliza a internet para jogar e $66 \%$ utiliza para o WhatsApp" (RETRATOS, 2016, p. 257), quando, nesse sentido, as tecnologias também podem ser utilizadas para fins educativos e culturais. É como se pudéssemos reverter os aparentes danos tecnológicos em benefícios de novo aprendizado: "As mudanças induzidas pelas tecnologias da comunicação (sobretudo celulares e iPads) continuarão a provocar um 'terremoto positivo' na vida das pessoas, assim como um aumento na oferta de cultura e uma diversificação de alternativas" (MASI, 2015, p. 304). Outro objetivo da biblioteca escolar segundo o manifesto da IFLA pode ser trazido aqui para o diálogo com a meta 4.2, no sentido do cuidado com uma educação pré-escolar que prepara para um desenvolvimento ao longo da vida: "defender a ideia de que a liberdade intelectual e o acesso à informação são essenciais à construção de uma cidadania efetiva e responsável e à participação na democracia" (IFLA 2000, p. 2).

$\mathrm{Na}$ meta 4.3, "educação técnica, profissional e superior de qualidade" (NAÇÕES, 2015a, p. 1). A biblioteca escolar acompanha a carreira educacional do aluno, contribuindo

\begin{tabular}{|c|c|c|c|}
\hline (C) RDBCI: Rev. Digit. Bibliotecon. Cienc. Inf. & Campinas, SP & v.16 & n. \\
\hline
\end{tabular}


para o seu desenvolvimento em todas as fases posteriores do aprendizado ao longo da vida. A biblioteca escolar é um centro de informação e cultura, portanto é necessário que se cuide da formação e disseminação do acervo por vários tipos de documentos e diferentes suportes informacionais. Outro objetivo da biblioteca escolar, segundo o manifesto da IFLA, pode ser convocado para o diálogo com a meta 4.3 do ODS 4, uma vez que permite uma relação direta com esta meta: "proporcionar oportunidades de utilização e produção de informação que possibilitem a aquisição de conhecimentos, a compreensão, o desenvolvimento da imaginação e o lazer" (IFLA 2000, p. 2).

Na meta 4.4, "habilidades relevantes, inclusive competências técnicas" (NAÇÕES, 2015a, p. 1). A biblioteca escolar fornece instrumental necessário para a formação, o desenvolvimento e o aprimoramento das competências do aluno. É ainda um espaço de criação e de compartilhamento de experiências. Cabe utilizar mecanismos técnicos e de políticas públicas para formação de redes de bibliotecas escolares, das competências de informação, tendo como foco principal a construção do conhecimento e a compreensão humana, implementadas por meio da pesquisa científica.

Neste sentido, uma rede pode ser considerada como [...] "uma organização formada por um conjunto de bibliotecas conectadas que se comprometem formalmente na consecução de objetivos comuns" (VARELA OROL; GARCÍA MOLERO; GONZÁLEZ GUITIAN, 1988, p. 218, tradução nossa). Logo, considera-se como um de seus objetivos o alcance da formação de novos leitores, produto de um projeto que pretende surgir no centro da rede nacional brasileira, como fio condutor ao caminho de uma transformação no aspecto do desenvolvimento da cidadania, da cultura e da educação. Podemos entender que uma rede de bibliotecas é importante para o desenvolvimento da prática de leitura e para a mediação da informação envolvendo o leitor, o bibliotecário e o acervo, na constituição de habilidades e competências. Assim, a rede funciona literalmente como uma série de conexões que formam e informam a propagação do conhecimento e a formação educacional.

Outro objetivo da biblioteca escolar segundo o manifesto da IFLA cabe no referencial da meta 4.4, já que prevê o estímulo à formação de habilidades e competências: "apoiar os alunos na aprendizagem e na prática de competências de avaliação e utilização da informação, independentemente da natureza e do suporte, tendo em conta as formas de comunicação no seio da comunidade" (IFLA 2000, p. 2). A biblioteca escolar faz diferença na aprendizagem do aluno e na formação do professor, pelas suas ações e evidências.

Na meta 4.5, sobre a eliminação de "disparidades de gênero na educação" (NAÇÕES, 2015a, p. 1). Com a disponibilização de seu acervo, acompanhada de atividades de difusão (encontros com autores, leituras comentadas, etc.), a biblioteca escolar contribuiria ainda para a ampliação da noção de gênero (dada a sua diversidade no mundo contemporâneo). A função civilizadora da biblioteca escolar permite a "igualdade de acesso a todos os níveis de educação" sem distinções sociais ou de gênero. Outro recurso de apoio seria efetuar

\begin{tabular}{|c|c|c|c|}
\hline (C) RDBCI: Rev. Digit. Bibliotecon. Cienc. Inf. & Campinas, SP & v.16 & \\
\hline
\end{tabular}


workshops para jovens e adultos, de modo a permitir que se entenda a questão de gênero na convivência escolar.

Na meta 4.6, o "básico de matemática" (NAÇÕES, 2015a, p. 1). Mencionando a alfabetização em nível "básico de matemática", esta meta pode ser estendida a todas as outras disciplinas que contribuem para uma existência plena do aluno-cidadão, configurando uma real competência em informação e afirmando o valor da habilidade considerada "necessária para o exercício pleno da cidadania", de acordo com a Organização para Cooperação e Desenvolvimento Econômico (OCDE). A biblioteca escolar participa e contribui para a melhoria dos níveis do PISA. É necessária a participação das secretarias estaduais e municipais da educação para a integração dos jovens nas escolas públicas.

$\mathrm{Na}$ meta 4.7, que trata da "cidadania global", em "que todos os alunos adquiram conhecimentos e habilidades" (NAÇÕES, 2015a, p. 1). A biblioteca escolar é, para os alunos, a porta de entrada para a sociedade do conhecimento e da informação. Está no início da competência em informação e, portanto, integra o "desenvolvimento sustentável" do aluno na cidadania. As bibliotecas escolares "devem ser espaços para criação e compartilhamento de conhecimento, não somente um espaço para consumo e empréstimo de livros. Sabemos que a função de uma biblioteca deve transcender as quatro paredes" (LANKES, 2016 p. 116). Impõem-se como lugar de encontro de pessoas. Na medida de suas atribuições e da extensão de suas ambições, ampliam o campo educacional para a esfera maior da sociedade, não circunscrita ao limitado e estreito quadrado entre suas estantes. Outro objetivo da biblioteca escolar, segundo o manifesto da IFLA, parece caber à justa medida na meta 4.7: "providenciar acesso aos recursos locais, regionais, nacionais e globais e às oportunidades que confrontem os alunos com ideias, experiências e opiniões diversificadas" (IFLA 2000, p. $3)$.

Uma possível resposta à meta 4.7 seria a participação de bibliotecas escolares em redes nacionais e internacionais, no sentido de busca e troca de experiências e projetos. Por outro lado, " $66 \%$ da população não frequentam bibliotecas ou frequentam raramente $14 \%$. Somente $5 \%$ da população frequentam sempre, e $15 \%$, às vezes. A biblioteca mais frequentada por quem frequenta sempre ou às vezes é a escolar, seguida da pública" (RETRATOS, 2016, p. 40). Tal diagnóstico encontra confirmação em outras fontes. Segundo Botelho (2016, p. 179), na pesquisa $O$ uso do tempo livre e as práticas culturais na região metropolitana de São Paulo, "Os dados apontaram que cerca de dois terços dos que leram pelo menos um livro por prazer não frequentaram uma biblioteca neste período".

Nesse sentido, o Estado deve ter a preocupação com o domínio da leitura nas bibliotecas escolares e com a continuidade nas bibliotecas públicas. É importante que, no Brasil, criem-se programas nacionais como o Program International Reading Literacy Study (PIRLS) da International Association for the Evalution of Education Achievement (IEA). Esse programa fornece dados internacionais sobre o quanto as crianças lêem, ao avaliar a

\begin{tabular}{|c|c|c|c|}
\hline (C) RDBCI: Rev. Digit. Bibliotecon. Cienc. Inf. & Campinas, SP & v.16 & n. \\
\hline
\end{tabular}


realização de leitura dos alunos. E também recolhe informações sobre: os sistemas educacionais nas políticas curriculares nacionais em leitura; como o sistema educacional é organizado para facilitar a aprendizagem; o ambiente doméstico dos estudantes para aprender; clima e recursos escolares; e como as instruções realmente ocorrem nas salas de aula.

A IEA é uma organização não governamental sem fins lucrativos, fundada em 1958, que, em conjunto com outras associações, realiza pesquisas comparativas em educação, fornecendo "dados de alta qualidade que apontam para fatores-chave que influenciam ensinando e aprendendo; que direcionam as reformas educacionais; e contribui para a pesquisa em avaliação educacional, desenvolvendo uma rede mundial de pesquisadores" (INTERNATIONAL, 2102). O Brasil é membro da IEA, mas poucos são os avanços para a perpetuação da biblioteca escolar nas escolas públicas, apesar da existência da Lei $12.244 / 2010$.

Na meta 4a, melhoria das "instalações físicas para educação" (NAÇÕES, 2015a, p. 1). Um dos pressupostos da biblioteca escolar é proporcionar um espaço social sem barreiras físicas: em vez de a sala de aula invadir a biblioteca, a biblioteca escolar é que começa a invadi-las, ocupá-las, e expandir seu perímetro de atuação. É como se a biblioteca criasse quase uma necessidade de redefinição da arquitetura da cidade em função dos usos do espaço público como lugar de convivência e aprendizagem: "Embora os bibliotecários precisem de cada vez menos espaço para trabalhar, a comunidade precisa de cada vez mais espaço para interagir e criar. As instalações das bibliotecas físicas estão sendo transformadas em um terceiro espaço" que pode ser qualquer ambiente de convívio social, como uma barbearia, uma praça ou um bar (LANKES, p. 129).

Cabe aproveitar as pesquisas nacionais e internacionais consolidadas sobre instalações ideais, tomando como sugestões de modelo para aplicação no âmbito da rede de bibliotecas escolares brasileiras. Cabe promover a integração com profissionais das mais distintas áreas de atuação em regime de integração de projetos comuns. Eis outro objetivo da biblioteca escolar, segundo o manifesto da IFLA, que pode ser chamado para o diálogo com as metas dos ODS, no caso da meta 4a: "organizar atividades que favoreçam a consciência e a sensibilização para as questões de ordem cultural e social” (IFLA 2000, p. 2).

A meta 4c, que trata "professores qualificados" e "formação de professores" (NAÇÕES, 2015a, p. 1). Além dos profissionais especializados, a biblioteca escolar deve contar com diversos profissionais. Parcerias com universidades geram cursos de especialização e mestrado profissional na área da biblioteca escolar. Cursos de biblioteconomia à distância são outro meio de direcionar o mercado de trabalho para as bibliotecas escolares. Por fim, trata-se de uma questão também de políticas públicas que visam a inserção do cargo de bibliotecário nas escolas dos municípios. É importante a formação contínua dos profissionais atuantes na biblioteca escolar, levando em conta o fato 
que o mundo está em constante mudança. Outro objetivo da biblioteca escolar, segundo o manifesto da IFLA, trata, em complemento à formação e à qualificação de professores, da ressignificação dos mesmos, incluídos na sequência de esforços partilhados: "trabalhar com alunos, professores, órgãos de gestão e pais de modo a cumprir a missão da escola" (IFLA 2000, p. 2).

Refletindo sobre estes tópicos do ODS 4, consideramos que, para um desenvolvimento sustentável, o profissional bibliotecário precisa aprender a trabalhar com equipes multi e interdisciplinares, na medida em que o trabalho com informação é, justamente por envolver múltiplas disciplinas, uma atividade complexa. Ainda para um bom desenvolvimento sustentável, são necessários o comprometimento ativo no planejamento de políticas de informação para o Brasil e o posicionamento atuante de agentes de transformação social (combinando as questões técnicas biblioteconômicas com as questões sociais mais amplas). Para a consecução da sustentabilidade, num mundo saturado de tecnologia, caberia ao profissional bibliotecário contribuir para a reestruturação dos canais de distribuição, disseminação e transferência de informação, com o objetivo de otimizar o uso da telecomunicação e das tecnologias de informação (ainda mais num cenário onde se gasta mais com tecnologia e menos com a questão social). Enfim, para um desenvolvimento sustentável, cabe ao bibliotecário ser um profissional eticamente e socialmente responsável, aberto e crítico, apto às adaptações das mudanças.

O ODS 4 permite perceber como é importante reforçar os elos da biblioteca escolar com o meio ambiente, com os meios social e cultural da comunidade, envolvendo áreas como economia, política e saúde, entre outras. A cooperação entre redes de bibliotecas escolares internacionais, particularmente nos países do Mercosul, na América do Sul e em países europeus de cultura e idioma latinos, permite o intercâmbio de informações e experiências.

\section{OUTROS ODS E A BIBLIOTECA ESCOLAR}

Objetivos como ODS 3 Saúde e Bem-Estar, ODS 6 Água Potável e Saneamento, ODS 7 Energia Limpa e Acessível, ODS 13 Ação contra a Mudança Global do Clima e ODS 16 Paz, Justiça e Instituições Eficazes, têm naturalmente abrigo no âmbito da biblioteca escolar, que inclui ações interdisciplinares e multimeios, como trabalhar com vídeo, a elaboração de pesquisas e bibliografia especializada aos usuários.

No ODS 8 "Trabalho Decente e Crescimento Econômico", o tópico da "modernização tecnológica e inovação" (NAÇÕES, 2015b, p. 1) toca diretamente os elementos básicos de uma rede de informação, que depende dos avanços e constantes atualizações tecnológicas para satisfazer suas funções de formação e informação. Noutro tópico, as questões de "empreendedorismo, criatividade e inovação" (NAÇÕES, 2015b, p. 1) são elementos complementares aos elementos especificamente educativos exigidos para a gestão de uma rede de bibliotecas escolares. 
O mesmo se dá com o ODS 9 "Indústria, Inovação e Infraestrutura” (NAÇÕES, 2015c, p. 1), que menciona explicitamente as tecnologias de informação e comunicação, que podem se estabelecer como suporte de recursos digitais e informacionais para melhorias no ensino e aprendizagem também na biblioteca escolar, mas que não justifica o esquecimento das questões sociais e educativas.

No ODS 10 "Redução das Desigualdades" (NAÇÕES, 2015d, p. 1), poderíamos acrescentar o pensamento de que, com a biblioteca escolar, pode contribuir para a formação da inclusão e ascensão cultural e social dos estudantes. Ao mencionar os países menos desenvolvidos, esta ODS sugere buscar modelos bem-sucedidos em países mais desenvolvidos, o que poderia propor o compartilhamento de experiências e modelos por meio de publicações que divulguem os projetos realizados.

No ODS 11 "Cidades e Comunidades Sustentáveis", o objetivo de "Fortalecer esforços para proteger e salvaguardar o patrimônio cultural e natural do mundo" (NAÇÕES, 2015e, p. 1) encontra lugar adequado no espaço da biblioteca, entendida como estação de conhecimento que, no caso da biblioteca escolar, agrega ainda o valor de educação e de formação.

No ODS 12 “Consumo e Produção Responsáveis” (NAÇÕES, 2015f, p. 1), a ideia de uma educação para a cidadania ancorada na biblioteca escolar também pode encontrar espaço, garantindo que a comunidade escolar tenha informação relevante e por meio de projetos que a biblioteca escolar pode conceber e realizar para a conscientização quanto ao desenvolvimento sustentável e estilos de vida em harmonia com a natureza

No ODS 17, que trata de "Fortalecer os meios de implementação e revitalizar a parceria global para o desenvolvimento sustentável" (NAÇÕES, 2015g, p. 1), a noção de redes de bibliotecas escolares, com suas trocas de experiências, modelos e tecnologias, revela-se um campo de aplicação e exploração deste mecanismo colaborativo. Nesse sentido, pensar a rede de bibliotecas como parte integrante do sistema nacional de ensino no Brasil, é tê-la como importante parceira na estratégia de melhoria da educação e combate aos aspectos que envolvam o insucesso escolar (PORTUGAL. MINISTÉRIO DA EDUCAÇÃO E CIÊNCIA, 2013).

Ainda nesse objetivo 17, quando se trata de "Aumentar a coerência das políticas para o desenvolvimento sustentável" e de "Respeitar o espaço político e a liderança de cada país para estabelecer e implementar políticas para a erradicação da pobreza e o desenvolvimento sustentável" (NAÇÕES, 2015g, p. 1), recai-se sobre um aspecto fundamental e urgente não apenas para a biblioteca escolar mas para a educação como um todo: a criação e o bom desenvolvimento de políticas públicas de caráter social e cultural. Enfim, para sua própria continuidade e sustentabilidade: 


\begin{abstract}
bem formuladas, essas políticas podem ter uma ação efetiva, pois representam uma dimensão que permite que se façam diagnósticos para atacar os problemas de maneira programada, estimar recursos e solucionar carências, mediante o estabelecimento de metas de curto, médio e longo prazo (BOTELHO, 2016, p. 23).
\end{abstract}

Outros ODS que não o ODS 4 podem comportar relações com a biblioteca escolar mesmo que não se refiram explicitamente a questão educacional, por outo lado, a biblioteca escolar pode oferecer recursos tecnológicos e informacionais em áreas tão diversas como saúde e economia.

\title{
CONCLUIR [...] PARA NÃO CONCLUIR
}

Esta investigação reflexiva procurou contribuir com informações e reflexões sobre a Agenda 2030 na clave da biblioteca escolar, dirigindo-se à sociedade em geral e aos pesquisadores acadêmicos, uma vez que as políticas públicas educacionais, sociais e culturais do Brasil ainda são embrionárias e, algumas vezes, não aplicadas. É fundamental que as entidades realizem as políticas públicas em parceria com bibliotecários e demais profissionais envolvidos com a biblioteca escolar e a leitura. Entretanto, há que se valorizar os esforços de alguns órgãos da classe biblioteconômica por demonstrarem preocupação com o problema que a leitura e as bibliotecas escolares enfrentam.

Este artigo intentou interpretar o Objetivo de Desenvolvimento Sustentável 4, integrante da Agenda 2030 programada pela ONU, segundo os parâmetros da biblioteca escolar. Apresentando os tópicos do ODS 4, tomado como núcleo desta investigação, por ser aquele mais relacionado e melhor identificado à educação. $\mathrm{O}$ artigo trouxe para cotejo e diálogo referências sobre a natureza e as funções da biblioteca escolar que pudessem instigar a reflexão a respeito de aspectos da educação brasileira, tendo em vista a noção de desenvolvimento sustentável para a nação.

A Agenda 2030 da ONU privilegia a educação primária, o que permite uma relação direta com a biblioteca escolar por conta de seu meio mesmo de atuação e "público alvo": crianças e adolescentes. Assim, foi possível estabelecer proposições ao redor de alternativas para a melhoria de qualidade de vida destes alunos, que são elementos constituintes de uma promessa de futuro.

Ao articular objetivos de desenvolvimento sustentável e objetivos da biblioteca escolar, foi possível desenhar um quadro em que a biblioteca escolar configura seu papel no espectro mais largo de uma política pública para a educação, justamente pela sintonia e afinidade com as diretrizes do desenvolvimento sustentável tal como projetado pela Agenda 2030. 
O ODS 4 da ONU permite perceber como é importante reforçar os elos da biblioteca escolar com o meio ambiente, com os meios social e cultural da comunidade, envolvendo áreas como economia, política, saúde e cultura. E como a biblioteca escolar tem uma função e uma contribuição das mais relevantes, apesar da pouca visibilidade de sua condição. A cooperação entre redes de bibliotecas escolares internacionais, particularmente nos países do Mercosul, na América do Sul e em países europeus de cultura e idioma latinos, possibilita o intercâmbio de informações e experiências.

A biblioteca escolar tem um papel decisivo na organização e na difusão do acervo de obras que versam sobre todas as áreas do conhecimento, incluindo questões como as de saúde pública, educação para a saúde, alimentação saudável, por exemplo. Sua configuração em redes permite o conhecimento, por meio do intercâmbio de informações e experiências, espelhando o processo mesmo da Agenda $2030 \mathrm{em}$ seu aspecto colaborativo, em um chamado às nações para que participem da iniciativa em prol de um bem comum.

Ao analisar as premissas da biblioteca escolar em aproximação a outras referências, como a Agenda 2030 da ONU e o Manifesto da IFLA, foi possível constatar e, espera-se, demonstrar, que a biblioteca escolar é peça fundamental num projeto eticamente generoso e responsável como o do desenvolvimento sustentável, para o planeta e a humanidade, a partir de algo tão vital, e ao mesmo tempo frágil (por estar sujeito não às intemperes da natureza mas sim aos desmandos de governos), como o ar que respiramos: a educação.

\section{REFERÊNCIAS}

ALVARENGA, Darlan. Economia. Brasil cai para a $90^{\mathrm{a}}$ posição em ranking de igualdade entre homens e mulheres, 2017. Disponível em:

https://g1.globo.com/economia/noticia/brasil-cai-para-a-90-posicao-em-ranking-deigualdade-entre-homens-e-mulheres.ghtml>. Acesso em: 02 de nov. 2017.

BOTELHO, Isaura. Dimensões da cultura: políticas culturais e seus desafios. São Paulo: Edições Sesc, 2016.

BRASIL. LEI N 9.394 de 20 de dezembro de 1996. Lei de Diretrizes e Bases da Educação Nacional. Brasília: Ministério da Educação, 1969. Disponível em:

<https://www2.senado.leg.br/bdsf/bitstream/handle/id/70320/65.pdf $>$. Acesso em: 12 jun. 2018.

CENTRO Regional de Informação das Nações Unidas. Objectivos de Desenvolvimento do Milénio: uma breve síntese. Portugal: UNRIC, 2010. Disponível em:< https://www.unric.org/html/portuguese/pdf/2010/MDGs-at-a-GlanceFINAL-pt.pdf>. Acesso em: 28 de out. 2017 
FOOD and Agriculture Organization of the United Nations. The State of Food Security and Nutrition in the World 2017. Rome: FAO, 2017. Disponível em: http://www.fao.org/3/aI7695e.pdf. Acesso em: 12 jun. 2018.

GIL, António Carlos. Métodos e técnicas de pesquisa social. São Paulo: Atlas, 1999.

GLOBAL Gender Gap Report. Results and Analysis. World Economic Forum: Genebra, 2017. Disponível em: <http://reports.weforum.org/global-gender-gap-report-2017/resultsand-analysis/>. Acesso em: 29 out. 2017.

IFLA. International Federation of Library Associations and Institutions. Diretrizes da IFLA para a biblioteca escolar. Lisboa: Rede de Bibliotecas Escolares, 2015. Disponível em: <https://www.ifla.org/files/assets/school-libraries-resource-centers/publications/ifla-schoollibrary-guidelines-pt.pdf $>$ Acesso em 12 jun. 2018.

IFLA. International Federation of Library Associations and Institutions. Diretrizes da IFLA sobre os serviços da Biblioteca Pública. Lisboa: IFLA, 2013. Disponível em: $\langle$ https://www.ifla.org/files/assets/hq/publications/series/147-pt.pdf $>$. Acesso em 12 jun. 2018.IFLA. Manifesto IFLA/UNESCO para biblioteca escolar. São Paulo: FEBAB, 2000

INTERNATIONAL Association for the Evaluation of Education Achievement. About US. IEA: Amsterdam, 2012.

LANKES, R. David. Expect more: melhores bibliotecas para um mundo complexo. São Paulo: FEBAB, 2016.

MARCONI, Marina de Andrade; LAKATOS, Eva Maria. Técnicas de pesquisa. São Paulo: Atlas, 2006.

MASI, Domenico de. Caminhos da cultura no Brasil. Rio de Janeiro: Sextante, 2015.

NAÇÕES Unidas no Brasil. 4 Educação de Qualidade: assegurar a educação inclusiva e equitativa e de qualidade, e promover oportunidades de aprendizagem ao longo da vida para todas e todos. Brasil: ONUBR, 2105a. Disponível em: < https://nacoesunidas.org/pos2015/ods4/> . Acesso em: 25 de out.2017.

NAÇÕES Unidas no Brasil. 8 Trabalho decente e crescimento econômico: promover o crescimento econômico sustentado, inclusivo e sustentável, emprego pleno e produtivo e trabalho decente para todas e todos. Brasil: ONUBR, 2105b. Disponível em: < https://nacoesunidas.org/pos2015/ods8/>. Acesso em: 25 de out.2017.

NAÇÕES Unidas no Brasil. 9 Indústria, Inovação e Infraestrutura: construir infraestruturas resilientes, promover a industrialização inclusiva e sustentável e fomentar a inovação. Brasil: ONUBR, 2105c. Disponível em: < https://nacoesunidas.org/pos2015/ods9/>. Acesso em: 25 de out.2017.

NAÇÕES Unidas no Brasil. 10 Redução das Desigualdades: reduzir a desigualdade dentro dos países e entre eles. Brasil: ONUBR, 2105d. Disponível em: < https://nacoesunidas.org/pos2015/ods10/>. Acesso em: 25 de out.2017. 
NAÇÕES Unidas no Brasil. 11 Cidades e Comunidades Sustentáveis: tornar as cidades e os assentamentos humanos inclusivos, seguros, resilientes e sustentáveis. Brasil: ONUBR, 2015e. Disponível em: https://nacoesunidas.org/pos2015/ods11/>. Acesso em: $25 \mathrm{de}$ out.2017.

NAÇÕES Unidas no Brasil. 12 Consumo e Produção Responsáveis: assegurar padrões de produção e de consumo sustentáveis. Brasil: ONUBR, 2015f. Disponível em: < https:// https://nacoesunidas.org/pos2015/ods12/>. Acesso em: 25 de out.2017.

NAÇÕES Unidas no Brasil. 17 Parcerias e meios de Implementação: fortalecer os meios de implementação e revitalizar a parceria global para o desenvolvimento sustentável. Brasil:

ONUBR, 2105g. Disponível em: < https://nacoesunidas.org/pos2015/ods17/>. Acesso em: 25 de out.2017.

ONU. Organização das Nações Unidas no Brasil. Documentos Temáticos: Objetivos de Desenvolvimento Sustentável $1 \cdot 2 \cdot 3 \cdot 5 \cdot 9 \cdot 14$. Brasília: ONUBR, 2017. Disponível em: < http://www.br.undp.org/content/dam/brazil/docs/publicacoes/documentos-tematicos-ods-072017.pdf >. Acesso em: 12 jun. 2018.

RETRATOS da leitura no Brasil. Rio de Janeiro: Sextante, 2016.

PORTUGAL. Ministério da Educação e Ciência. Programa Rede de Bibliotecas Escolares: quadro estratégico: 2014-2020. Lisboa: Ministério da Educação e Ciência, 2013.

PROGRAMA das Nações Unidas para o Desenvolvimento no Brasil. Atingir o Ensino Básico Universal. PNUD: Brasil, 2015b. Disponível em: <

http://www.br.undp.org/content/brazil/pt/home/post-2015/sdg-overview1/mdg2.html > Acesso em: 26 out. 2017.

PROGRAMA das Nações Unidas para o Desenvolvimento no Brasil. Combater o HIV/Aids, a malária e outras doenças. PNUD: Brasil, 2015d. Disponível em: < http://www.br.undp.org/content/brazil/pt/home/post-2015/sdg-overview1/mdg6.html . Acesso em: 26 out. 2017.

PROGRAMA das Nações Unidas para o Desenvolvimento no Brasil. Estabelecer uma parceria mundial para o desenvolvimento. PNUD: Brasil, 2015f. Disponível em: < http://www.br.undp.org/content/brazil/pt/home/post-2015/sdg-overview1/mdg8.html >. Acesso em: 26 out. 2017.

PROGRAMA das Nações Unidas para o Desenvolvimento no Brasil. Garantir a sustentabilidade ambiental. PNUD: Brasil, 2015e. Disponível em: < http://www.br.undp.org/content/brazil/pt/home/post-2015/sdg-overview1/mdg7.html . Acesso em: 26 out. 2017.

PROGRAMA das Nações Unidas para o Desenvolvimento no Brasil. Melhorar a saúde materna. PNUD: Brasil, 2015c. Disponível em: $<$ http://www.br.undp.org/content/brazil/pt/home/post-2015/sdg-overview1/mdg1/>. Acesso em: 26 out. 2017. 
PROGRAMA das Nações Unidas para o Desenvolvimento no Brasil. Redução da pobreza. PNUD: Brasil, 2015a. Disponível em: <http://www.br.undp.org/content/brazil/pt/home/post2015/sdg-overview1/mdg1/>. Acesso em: 26 out. 2017.

UNICEF. Levels and trends in child mortality. New York: United Nations Children's Fund, 2017. Disponível em: http://www.unicef.pt/docs/pdf_publicacoes/Levels-an-TrensChild-Mortality.pdf. Acesso em: 25 de out. 2017.

VARELA OROL, C.; GARCÍA MOLERO, L. A.; GONZÁLEZ GUITIAN, C. Redes de biblioteca. Boletín de la ANABAD, v. 38, n. 1-2, p. 215-242, 1988.

Disponível em: 〈http://dialnet.unirioja.es/descarga/articulo/904109.pdf $>$. Acesso em: 28 out. 2017.
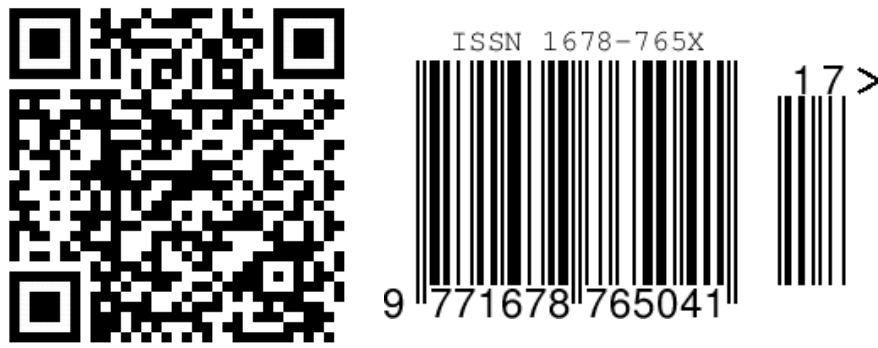